Krystyna Mihułka

Uniwersytet Rzeszowski

kmihulka@gmail.com

\title{
KONCEPCJE KULTURY A NAUCZANIE I UCZENIE SIĘ JĘZYKÓW OBCYCH - ZARYS TEORETYCZNY
}

\section{The concepts of culture versus foreign language teaching and learning: a theoretical outline}

Culture has been the subject of researchers' consideration for centuries, which is confirmed by hundreds of published definitions of the word culture. Even a perfunctory analysis of those definitions indicates that it is difficult to talk about culture using it as a consistent concept. The aim of this article is therefore to highlight the richness of meaning of the word culture by presenting and discussing the characteristics of culture which appear most frequently in definitions developed by social psychologists, cultural anthropologists, social pedagogues, foreign language acquisition researchers, and students of German philology. The final part of this article presents those features of culture which allow to place this concept correctly in the process of foreign language teaching and learning.

Keywords: culture, cultural studies, socialization / enculturation, a foreign language lesson

Słowa kluczowe: kultura, wiedza o kulturze, socjalizacja/enkulturacja, lekcja języka obcego

\section{Wprowadzenie}

Kultura jest przedmiotem dociekań badaczy już od stuleci, o czym świadczą setki opublikowanych definicji. Już ich pobieżna analiza pokazuje, że trudno mówić o pojęciu spójnym pod względem znaczeniowym, gdyż kultura zaskakuje 
mnogością interpretacji zarówno w dyskursie naukowym, jak i w potocznym użyciu. Nie ma definicji kultury uniwersalnie „lepszych” lub „gorszych”. Można zatem mówić jedynie o definicjach bardziej lub mniej użytecznych dla określonego rodzaju badań.

Na trudności związane z interpretacją pojęcia kultura zwracało uwagę wielu badaczy (np. Grucza, 1989; Roth, 2002; Altmayer, 2004; Roche, 2006; Haller i Nögele, 2013; Bolten, 2014), podkreślając jednocześnie, że niewiele jest słów tak niejednoznacznych jak kultura. Baecker (2003: 33) wyraża wręcz przekonanie o niemożliwości określenia tego pojęcia, sugerując jednocześnie, że wszelkie próby jego zdefiniowania wydają się mało sensowne i skazane na niepowodzenie. Ze stwierdzeniem Baeckera można się zgodzić jedynie częściowo, że kultury nie sposób zdefiniować jednoznacznie. Istniejących definicji, prób zdefiniowania i typologii kultury nie należy jednak traktować jako nic nieznaczących działań, gdyż dostarczają pewnych ram interpretacyjnych tego pojęcia, zwracając uwagę na wybrane jego aspekty, właściwości, cechy.

Kultura to pojęcie przywoływane także w kontekście nauczania i uczenia się języka obcego. Niestety, również i tutaj brak definicji powszechnie obowiązującej i w miarę koherentnej. Różnice w ujmowaniu pojęcia dają się zaobserwować wśród glottodydaktyków, tak przedstawicieli nauki, jak i praktyków. Brak konsensusu skutkuje m.in. tym, że podczas lekcji języka obcego pewne aspekty kultury są przesadnie gloryfikowane, podczas gdy inne zupełnie pomijane lub omawiane powierzchownie (Aleksandrowicz-Pędich, 2005, 2007; Mihułka, 2012a). Taki sposób postępowania nie sprzyja rozwijaniu kompetencji interkulturowej u uczniów, a co za tym idzie nie pozwala na pełne przygotowanie ich do komunikacji z przedstawicielami odmiennych kultur.

Celem niniejszego artykułu jest ukazanie bogactwa znaczeniowego słowa kultura poprzez nazwanie i omówienie właściwości i cech kultury najczęściej przywoływanych w definicjach stworzonych przez psychologów społecznych, antropologów kultury, pedagogów społecznych i glottodydaktyków oraz wymienionych podczas badania statycznego przez studentów filologii germańskiej (w większości przyszłych nauczycieli języka niemieckiego), dla których kultura jest, a przynajmniej powinna być, jednym z podstawowych pojęć. W końcowej części artykułu zostały zaprezentowane pewne sugestie zmian, których uwzględnienie mogłoby przyczynić się do pełniejszego poznania tego pojęcia przez osoby uczące się języka obcego oraz do właściwego usytuowania go w procesie nauczania języka obcego przez osoby odpowiedzialne za jego przebieg. 


\section{Wybrane aspekty kultury - charakterystyka}

Znaczenie słowa kultura ewoluowało na przestrzeni wieków, oddalając się coraz bardziej od swoich etymologicznych korzeni, tj. łacińskiego słowa colere ${ }^{1}$. Znaczne zmiany dają się także zauważyć pod względem pojemności znaczeniowej kultury ${ }^{2}$. I chociaż obecnie rozumiana jest szeroko, nie oznacza to wcale, że powstające w ostatnich dziesięcioleciach definicje można uznać za spójne. Dają się zaobserwować $w$ nich pewne punkty styczne, a jednym z nich jest niewątpliwie odchodzenie od oceniającego na rzecz opisowego pojmowania kultury.

W celu uchwycenia złożoności znaczeniowej słowa kultura zostały omówione wybrane aspekty, takie jak kultura vs natura, statyczne vs dynamiczne koncepcje kultury, związek człowieka z kulturą, kultura jako zjawisko społeczne, kultura jako zjawisko regularne oraz kultura jako zbiór zjawisk wyuczonych.

\subsection{Kultura vs natura}

W ramach holistycznej/globalnej koncepcji kultury, która w porównaniu z innymi ujęciami odznacza się najszerszym zasięgiem granic, kultura jest czymś przeciwstawnym względem natury. W myśl tej koncepcji kulturq jest to wszystko, co nie jest naturą, ale jest wytworem świadomego i celowego działania człowieka. Kultura określa zatem, jak zauważa Nieke (2008: 41), zarówno proces, jak i produkt końcowy wszelkich przekształceń natury przez człowieka, dlatego obejmuje ona i uprawę roli, i religię.

Rozgraniczenie natury i kultury ma swoje korzenie w przemyśleniach niemieckiego filozofa żyjącego w XVII wieku, Samuela Pufendorfa, który przeciwstawił kulturę (łac. cultura animi) naturze (łac. status naturale). Przemyślenia i stwierdzenia współczesnych badaczy (np. Grucza, 1989: 10-11; Krezenbacher, 1992: 171-172; Tarasiewicz, 2011: 73) skłaniają ku konstatacji, że dychotomia stawiająca na przeciwległych biegunach naturę i kulturę jest jednak zbyt radykalna i w sumie nie do końca uzasadniona. Np. Finke (2006 za Bolten, 2014: 93) jest zdania, że mówiąc o przyszłości kultury i natury, należy używać określenia połqczenie koewolucyjne. Ich pojęciowe rozgraniczenie nie jest wprawdzie pozbawione sensu, ale o wiele ważniejsze jest jednak to, aby pojęcia

\footnotetext{
${ }^{1}$ Etymologii słowa kultura poświęcił wiele uwagi Bolten (2006: 23, 26; 2014: 86-90).

${ }^{2}$ Obserwujemy wyraźne przejście od tradycyjnego, wąskiego pojmowania kultury, poprzez tzw. pojęcie poszerzone (charakterystyczne dla niemieckiego obszaru językowego) aż po otwarte czy też szerokie ujęcie kultury. Szerzej na temat tradycyjnego, poszerzonego i szerokiego pojęcia kultury w: Altmayer (1997: 2-5; 2004: 78-82); Bolten (2006: 22-27); Kretzenbacher (1992: 172-179).
} 
te postrzegać jako całość. Tak właśnie postrzega je Grucza (1989: 12), dla którego „kultura jest czymś ściśle splecionym z naturą, czymś, co w naturze jakby drzemało i zostało z niej wydobyte przez człowieka". Inny argument podający w wątpliwość dychotomię kultura - natura przytacza Nieke (2008: 41), podkreślając, że „obecnie coraz trudniej jest znaleźć naturę zupełnie niezmienioną przez człowieka". To, co powszechnie bywa określane mianem natury, tak naprawdę nią nie jest, ponieważ zostało w większym lub mniejszym stopniu, bezpośrednio lub pośrednio, celowo lub przypadkowo, przekształcone przez człowieka, czego przykładem są rezerwaty przyrody. Zgodnie z tym tokiem rozumowania niemal wszystko jest obecnie kulturą, która, jak stwierdza cytowany autor, staje się jedynym możliwym sposobem i formą życia.

\subsection{Statyczne vs dynamiczne koncepcje kultury}

Mimo że obecnie kultura jest utożsamiana z procesem, a więc czymś dynamicznym i ciągłym (np. Weber, 1976; Altmayer, 1997; Roth, 2002; Roche, 2006; Wolf, 2010), należy pamiętać również o innych teoriach kultury, nazywanych koncepcjami redukcyjnymi lub selektywnymi. Charakteryzują się one tym, że do obszaru kultury zaliczana jest tylko pewna jego część.

Nawiązujące do Kanta rozgraniczenie między kulturą i cywilizacją (np. Bausinger, 1975; Kretzenbacher, 1992; Roth, 2002: 270-271; Altmayer, 2004: 82-83; Kübler, 2011: 18-20; Tarasiewicz, 2011) jest najbardziej znanym - przynajmniej w niemieckim obszarze językowym - przykładem redukcyjnej koncepcji kultury. Podczas gdy cywilizacja obejmuje przekształcenia dokonane przez człowieka umożliwiające w ogóle życie z innymi ludźmi w obrębie wspólnoty w dzikim środowisku naturalnym, czyniąc je znośnym, niekiedy wręcz przyjemnym, to kultura odnosi się do przekształceń, które mogą uchodzić za wytwory ludzkiego umysłu niezorientowane na osiągnięcie jakiegoś konkretnego celu; chodzi głównie o sztukę, religię, filozofię (Nieke, 2008: 42). Inaczej rzecz ujmując, do cywilizacji zalicza się te osiągnięcia i rezultaty działań ludzkich, które można określić mianem użytkowych, do kultury zaś dokonania i wytwory natury duchowej.

W redukcyjnych koncepcjach kultury mających - zaznaczmy to wyraźnie - charakter umowny, kultura jest traktowana w sposób statyczny i segmentalny, co godzi w jej naturę. Kultura obejmuje bowiem nie tylko gotowe produkty, lecz także proces kultywacji. Cechuje ją zatem dynamika; ona nieustannie się rozwija, zmienia, co w trafny sposób ujął Altmayer (1997: 12), stwierdzając, że „kultura jest stale w ruchu”. 


\subsection{Związek człowieka z kulturą}

Związek człowieka z kulturą Dakowska (2008: 66) nazywa związkiem interakcyjnym: człowiek tworzy kulturę, a kultura wpływa na kształtowanie się mentalności jednostek. Człowiek jest zatem twórcą kultury ${ }^{3}$, konstruuje ją w sposób aktywny i kreatywny, ale jest zarazem przez nią kształtowany. Związek ten można analizować na różne sposoby. Np. w teorii antropocentrycznej kultura jawi się jako fakt indywidualny, a istotą generującą kulturę (ale także język i wiedzę) jest każdy konkretny człowiek (Grucza, 1992; Bonacchi, 2011). W definicjach kultury wpisujących się w perspektywę społeczną człowiek pojawia się zawsze jako członek określonej społeczności.

\subsubsection{Kultura jako zjawisko społeczne}

Kultura nie powstaje i nie rozwija się w próżni, lecz jest wynikiem ścisłego, wzajemnego odziaływania i przenikania się płaszczyzn - politycznej, społecznej i ekonomicznej - kształtowanych przez ludzi (Altmayer, 1997: 12). Relacje zachodzące pomiędzy kulturą i społeczeństwem określa się mianem związku synergicznego - nie ma kultury bez społeczeństwa i społeczeństwa bez kultury (Dakowska, 2008: 66). Kultura jest związana z człowiekiem jako istotą prowadzącą społeczny tryb życia. Poszczególne jednostki wnoszą swój wkład w rozwój kultury, jednak istnieje ona tylko dzięki życiu zbiorowości. Tak rozumiana kultura wydaje się czymś ponadjednostkowym.

W znacznej większości koncepcji kultury, poczynając od pierwszej niewartościującej definicji Tylora (1871: 1), akcentowany jest fakt, że kulturę człowiek tworzy, ale i nabywa jako członek danej społeczności (Lexis, 1906: 1; Meyers Lexikon, 1924: 299), oraz że kultury nie należy postrzegać jako prostej sumy wytworów poszczególnych osób, lecz jako wspólny produkt powstały na skutek wzajemnych powiązań społecznych (Lexis, 1906: 1). Podczas gdy w powyższych

\footnotetext{
${ }^{3}$ Stwierdzenie „człowiek jest twórcą kultury” sugeruje, że każdy człowiek posiada zdolności kulturotwórcze. Gdy jednak przeanalizujemy definicję kultury opublikowaną w Meyers Lexikon (1939: 17) dowiemy się, że to rasa decyduje o tym, czy ktoś posiada zdolności kulturotwórcze, czy też nie. Biorąc powyższe pod uwagę, przedstawiciele tylko wybranej rasy, a nie wszyscy ludzie, mogą tworzyć dobra i wartości kulturowe. Warto podkreślić, że już z początkiem XX wieku Lexis (1906: 6-7) zastanawiał się nad tym, czy w ogóle, a jeśli tak, to na ile, rasa ma wpływ na kształtowanie kultury przez człowieka. Różnice rasowe rozpatrywał on jednak inaczej niż zwolennicy faszyzmu, tj. w kategoriach zdolności językowych wszystkich ras, wspólnych i odmiennych cech w budowie anatomicznej człowieka, w tym koloru skóry, różnic w obrębie cech fizjologicznych (np. siła mięśni, ostrość zmysłów, odporność na określone choroby etc.) oraz różnic o podłożu intelektualnym.
} 
definicjach zaznacza się, że kultura odzwierciedla ogół zjawisk i sposobów życia danej społeczności, tak w definicji kultury z 1939 roku (Meyers Lexikon, 1939: 16-17) dają się zauważyć wyraźne wpływy ideologii faszystowskiej - wspólna rasowo-narodowa substancja jest fundamentem kultury, która obejmuje tylko zdrowe przejawy życia danego ludu (narodu) lub rasowo określonej wspólnoty społecznej.

W okresie powojennym istniało wiele definicji kultury, które zostały sformułowane na bazie różnorodnych punktów odniesienia. Nazywano je definicjami anatomicznymi. Kulturę zwykło się wówczas ujmować jako bardziej lub mniej przypadkowy zbiór pewnych czynników określających daną grupę społeczną. Przełomowe wydają się zatem wysiłki podjęte przez amerykańskich antropologów mające na celu pogrupowanie wówczas obecnych definicji kultury, a w efekcie wskazanie cech i właściwości kultury najczęściej przywoływanych w wymienionych koncepcjach. Kroeber i Kluckhohn (1952: 41-73) poddali wnikliwej analizie ponad 160 definicji kultury ${ }^{4}$, koncentrując się przy tym na sześciu zasadniczych punktach odniesienia, takich jak deskryptywność, historyczność, normatywność, podłoże psychologiczne, strukturalność i (nie)genetyczność. Na podstawie tej analizy kultura jawi się jako ogół wzorców zachowania (myślenia, odczuwania i reagowania) ukształtowanych historycznie, obowiązujących i akceptowanych w obrębie danej grupy społecznej, nabywanych i przekazywanych z pokolenia na pokolenie za pośrednictwem symboli. Wzorce te stale służą jako potencjalne wytyczne regulujące ludzkie postępowanie. Powyższe ujęcie wydaje się stanowić punkt wyjścia dla szerokiego pojmowania kultury. W obecnych koncepcjach kultura postrzegana jest jako pewien rodzaj zinternalizowanej wiedzy o wartościach, normach, regułach, zasadach i wyobrażeniach preferowanych w ramach danej społeczności, która uzewnętrznia się w formie ludzkich wytworów materialnych i mentalnych (Mihułka, 2012a: 23).

\subsection{Kultura jako zjawisko regularne}

Kolejną cechą kultury jest jej regularność - zjawiska kulturowe zachodzą w obrębie wspólnoty z pewną częstotliwością. Chodzi głównie o zachowania, przekonania, poglądy, odczucia, ale także ich materialne i niematerialne manifestacje, które są rozpowszechnione w ramach tej społeczności, akceptowane i dzielone przez jej członków. Niemniej jednak najbardziej istotne, biorąc pod uwagę relacje międzyludzkie, są nie spektakularne wytwory kultury, jak np. dzieła malarstwa czy architektury, lecz te sprowadzające się do zbiorów zasad określających działania podejmowane przez człowieka.

${ }^{4}$ Broszinsky-Schwabe (2011: 68) zaznacza, że obecnie liczbę definicji kultury szacuje się na około 300 . 
Nowicka (2006: 51) zauważa, że jako przejaw kultury powinny być traktowane takie zjawiska, które powtarzają się i w związku z tym można je ujmować $\mathrm{w}$ prawa ${ }^{5}$. W wielu definicjach obecnych $\mathrm{w}$ literaturze przedmiotu kultura jest określana jako społecznie produkowany, reprodukowany i modyfikowany "system orientacyjny" (Auernheimer, 1988: 97; Thomas, 1994: 158; Thomas, 2003: 112; Nieke, 2008: 65), który składa się ze specyficznych wzorców orientacyjnych pozwalających na poprawne funkcjonowanie w konkretnej kulturze. Kluczowymi elementami tego systemu są wszelkie sposoby postrzegania, myślenia, wartościowania i działania uznane przez większość członków danej kultury za normalne i wiążące, przez nich akceptowane i preferowane, nie tylko w ramach tej wspólnoty, lecz w ogóle. Tylko osoby przestrzegające tych praw można uznać za kulturalne.

\subsection{Kultura jako zbiór zjawisk wyuczonych}

W znacznej większości koncepcji i teorii kultury uwypukla się fakt, że kultura nie jest wrodzona, nie jest przekazywana za pośrednictwem genów, lecz nabywa się ją w procesie uczenia się (Kroeber i Kluckhohn, 1952: 64-70). Na ten fakt zwraca uwagę również Hofstede (1993: 20) w modelu mentalnego zaprogramowania człowieka, akcentując, że kultura, jako „kolektywistyczne programowanie umysłu”, wywodzi się z naszego otoczenia społecznego, a nie z genów. Kulturę nabywamy zatem w procesie socjalizacji. W literaturze przedmiotu, w celu wyraźnego oddzielenia procesu nabywania kultury rodzimej od procesu nabywania kultury obcej, używa się określenia enkulturacja (inkulturacja). Jest ona rozumiana jako proces wrastania we własną, rodzimą kulturę, który rozpoczyna się od dnia narodzin dziecka i prowadzi do „rozumienia jej, zakorzenienia się w niej i jej wartościach"7 (Nikitorowicz, 2009: 503). Nabywanie kultury może przebiegać zatem w różnoraki sposób - świadomy i zamierzony, ale także przypadkowy i niezamierzony, czy nawet nieświadomy (jak w okresie wczesnego dzieciństwa). Uczenie się kultury może być wynikiem pasywnego imitatorstwa lub świadomego instruktażu.

\footnotetext{
${ }^{5}$ Bardziej przychylam się do rygorystycznego podejścia w kwestii uznawania danych zjawisk jako przejawów kultury, tzn. uważam, że powinny być one respektowane przez większość członków społeczności, a nie pojawiać się jedynie incydentalnie.

${ }^{6}$ Przymiotnik kulturalny obecny w języku potocznym pochodzi od wartościującego pojęcia kultura. W słowach kulturalny, niekulturalny zawiera się pochwała lub nagana, a więc pewna informacja będąca podstawą dla sformułowania oceny (por. Nowicka, 2006: 47-48). 7 Integracja z kulturą określonej społeczności jest ściśle związana z nabyciem specyficznego kodu językowego, przy pomocy którego członkowie tej społeczności interpretują rzeczywistość, wyrażają swoje myśli oraz się komunikują.
} 
W społecznych ujęciach kultury człowiek nie jest traktowany tylko jako istota biernie przejmująca kulturę otoczenia, gdyż nie tylko asymiluje on zastany materiał kulturowy, lecz także przetwarza go, przypisując mu swoiste indywidualne znaczenie (por. Nikitorowicz, 2007: 202; Nieke, 2008: 45). Podstawę stanowi jednak kultura zakorzeniona w danym środowisku społecznym, która jest punktem wyjścia dla wszelkich indywidualnych działań. Proces nabywania wzorców orientacyjnych i szablonów działań jest indywidualny, w związku z czym pojawiają się pewne mniejsze lub większe odstępstwa od powszechnie przyjętych reguł, które z czasem mogą zastąpić obowiązującą normę.

\section{Kultura w oczach studentów - opis badania}

Wysoka częstotliwość użycia słowa kultura w różnych kontekstach komunikacyjnych może sugerować, że mimo nakreślonych wyżej trudności interpretacyjnych mamy do czynienia ze słowem powszechnie znanym i rozumianym. Słowo kultura, wchodzące w skład podstawowych pojęć w kształceniu filologicznym, powinno być znane także studentom filologii germańskiej, przy czym oczekuje się od nich bardziej pogłębionego, a nie szablonowego rozumienia tego pojęcia. Przed przeprowadzeniem badania została postawiona teza, że interpretacje słowa kultura dokonane przez studentów filologii germańskiej (po czterech semestrach studiów) będą opierały się nie tylko na potocznym użyciu tego słowa, lecz będą także posiadały odpowiednią nadbudowę naukową. W celu potwierdzenia lub odrzucenia powyższej tezy w maju 2015 roku przeprowadzono badanie wśród studentów II roku studiów pierwszego stopnia filologii germańskiej Uniwersytetu Rzeszowskiego. Badana populacja została dobrana w sposób celowy, a biorąc pod uwagę jej wielkość - 38 osób, z czego 26 to członkowie grup specjalizacji nauczycielskiej - zaliczana jest do prób „przejściowych” (Łobocki, 2009: 175). Opisywane badanie to badanie o charakterze poprzecznym, które w literaturze przedmiotu określane jest także mianem diagnozy poprzecznej (Komorowska, 1982: 172-190) lub badaniem statycznym (Wilczyńska i Michońska-Stadnik, 2010: 62-63). Opiera się na metodzie wolnych skojarzeń zaliczanej do otwartych technik gromadzenia danych. Uczestniczący w badaniu studenci zostali poproszeni o podanie w formie pisemnej swoich skojarzeń ze słowem kultura oraz o „zdefiniowanie” tego pojęcia. Badanie było anonimowe, a uczestnictwo w nim dobrowolne.

Zebrane dane ukazały dość szeroki wachlarz studenckich interpretacji słowa kultura ${ }^{8} .55 \%$ badanych zaznaczyło, że „istnieje wiele definicji kultury” oraz

\footnotetext{
${ }^{8}$ Dla porównania warto przeanalizować wypowiedzi niemieckich studentów uczestniczących w badaniu przeprowadzonym przez Rotha (2002: 298-301).
} 
że ,jest ona interpretowana przez przedstawicieli różnych nauk na różne sposoby". Zebrany materiał badawczy poddano analizie ilościowej i jakościowej. Wypowiedzi studentów, dotyczące tematycznej zawartości pojęcia kultura, przyporządkowano do względnie jednolitych, niekiedy wzajemnie przenikających się grup znaczeniowych, które zostały omówione w podrozdziale 2. Trzeba jednak podkreślić, że aspektów kultury wyróżnionych w tabeli 1 (grupa właściwości) nie należy traktować jako zamkniętych całości, gdyż wzajemnie się one przenikają i uzupełniają, a wyodrębnione zostały jedynie w celu ich systematyzacji.

\begin{tabular}{|c|c|c|c|}
\hline Lp. & KULTURA & $w \%$ & Grupa właściwości \\
\hline 1. & $\begin{array}{l}\text { zbiór norm / zasad regulujących zachowanie; sposób } \\
\text { zachowania }\end{array}$ & 82 & \multirow{3}{*}{ kultura jako zjawisko regularne } \\
\hline 2. & tradycja, religia, zwyczaje, obyczaje & 66 & \\
\hline 3. & dobre wychowanie; kulturalne zachowanie & 50 & \\
\hline 4. & $\begin{array}{l}\text { związana z człowiekiem, jego kulturotwórczymi zdol- } \\
\text { nościami }\end{array}$ & 50 & $\begin{array}{l}\text { związek człowieka z kulturą; } \\
\text { kultura jako zjawisko społeczne }\end{array}$ \\
\hline 5. & $\begin{array}{l}\text { w tradycyjnym, wąskim ujęciu: arcydzieła malar- } \\
\text { stwa, architektury, literatury etc. }\end{array}$ & 47 & $\begin{array}{l}\text { statyczne vs dynamiczne } \\
\text { koncepcje kultury }\end{array}$ \\
\hline 6. & wyuczona; przekazywana z pokolenia na pokolenie & 37 & $\begin{array}{l}\text { kultura jako } \\
\text { zbiór zjawisk wyuczonych }\end{array}$ \\
\hline 7. & przeciwieństwo natury & 32 & kultura vs natura \\
\hline 8. & w sensie kultury narodowej & 26 & $\begin{array}{l}\text { związek człowieka z kulturą; } \\
\text { kultura jako zjawisko społeczne }\end{array}$ \\
\hline 9. & wydarzenia kulturalne; instytucje kultury & 16 & potoczne rozumienie kultury \\
\hline 10. & $\begin{array}{l}\text { obejmuje wytwory materialne i mentalne (du- } \\
\text { chowe) }\end{array}$ & 13 & $\begin{array}{l}\text { kultura jako } \\
\text { zbiór zjawisk wyuczonych }\end{array}$ \\
\hline
\end{tabular}

Tabela 1: Znaczenie słowa kultura w oczach ankietowanych studentów.

Na podstawie zgromadzonych danych można stwierdzić, że badani studenci preferują społeczne i relatywistyczne pojmowanie kultury. Znaczna większość z nich (82\%) postrzega ją jako zbiór norm warunkujących zachowanie członków danej społeczności - „kultura jest dla mnie zbiorem ustalonych przez społeczeństwo norm i zachowań”; „kultura to dla mnie także normy, które powinno się przestrzegać”; ,"kultura to określony wzór zachowania i myślenia". Dwie trzecie respondentów utożsamia kulturę z tradycją, religią, zwyczajami i obyczajami, a więc także pewnymi regularnymi i powtarzającymi się zjawiskami - „kultura dla mnie to rozpowszechniona w danym kraju tradycja”; „kultura to zwyczaje i obyczaje rozpowszechnione w kraju, np. w Polsce”.

Połowa uczestniczących w badaniu studentów rozumie kulturę potocznie w kategoriach dobrego/kulturalnego zachowania (kultury osobistej), u którego podstaw leży wartościujące pojmowanie kultury. Potwierdzają to poniższe wypo- 
wiedzi badanych: „Moim zdaniem kultura to coś, co każdy sobą reprezentuje. Powiedzenie sąsiadowi »dzień dobry«, pomoc innym, ale też odpowiednie zachowanie się”; „czytanie książek jest również częścią kultury”; „Kultura to dobre wychowanie - traktowanie starszych osób z szacunkiem, odpowiednie zachowanie się przy stole”; „Kultura osobista wyznacza, co wypada, a co nie w określonych sytuacjach”; „Człowiek kulturalny to osoba, która odnosi się z szacunkiem do innej osoby, używa zwrotów »proszę", »dziękuję« itp.".

$50 \%$ badanych zwraca uwagę na ścisły związek człowieka i kultury („kultura to coś, co określa nas jako ludzi, a nie zwierzęta"), podkreślając jednocześnie kulturotwórcze zdolności człowieka („„człowiek jest jedyną istotą żywą tworzącą kulturę”), przy czym zaznaczali oni, że „człowiek jest zawsze członkiem określonej społeczności”, najczęściej narodowej. Jedna czwarta uczestniczących w badaniu studentów postrzega bowiem kulturę w kategoriach kultury narodowej, preferując tym samym polityczną perspektywę podczas określania granic kultury - „Można powiedzieć, że każdy kraj ma swoją kulturę”; „Każdy kraj, państwo tworzy swoją własną kulturę”; "Co kraj, to obyczaj. Polska kultura jest przecież inna niż niemiecka".

Wytwory kultury dają się przyporządkować zdaniem badanych (13\%) do dwóch grup, tj. wytworów mentalnych i materialnych. Prawie połowa uczestniczących w badaniu studentów (47\%) utożsamia kulturę tylko z wytworami materialnymi, dodajmy spektakularnymi, do których zaliczają arcydzieła z zakresu literatury i sztuki. Ograniczają oni zatem pojemność znaczeniową kultury tylko do jego tradycyjnego, tj. wąskiego, pojmowania.

$37 \%$ uczestniczących w badaniu studentów zauważa, że kultura nie jest dziedziczona, lecz wyuczona - „Kultura jest wyuczona i przekazywana z pokolenia na pokolenie”; „Kultura to wyuczone zachowania”; „Sposób, w jaki się zachowujemy jest wyuczony. Tak więc i kultury można się nauczyć”. Na uwagę zasługuje również fakt, że jedna trzecia badanych wyraźnie przeciwstawia kulturę naturze „Kultura to nie natura”; „Kultura jest wytworzona przez człowieka, natura nie”.

Nie bez znaczenia są także inne sugerowane przez studentów ujęcia kultury, wpisujące się raczej w wachlarz potocznych interpretacji. Oprócz wspomnianego wyżej rozumienia kultury jako „dobrego wychowania” chodzi także o kojarzenie kultury z instytucjami promującymi kulturę rozumianą wąsko: teatry, filharmonie, muzea itp.

Skojarzenia studentów ze słowem kultura oraz ich próby zdefiniowania kultury mogą z jednej strony napawać optymizmem, gdyż już po czterech semestrach studiowania na specjalności filologia germańska spektrum interpretacji słowa kultura jest dość obszerne i nie ogranicza się tylko do jego potocznych użyć. Z drugiej zaś strony bardziej szczegółowa analiza studenckich wypowiedzi pokazuje, że ich pojmowanie kultury opiera się nierzadko na etykietach, 
a nie na pogłębionej wiedzy, jest dość chaotyczne, a prezentowane myśli niekiedy wykluczają się: „Kultura to pojęcie ogólne, nie jest ona związana z jakimś narodem. [...] Co kraj, to obyczaj. Polska kultura jest przecież inna niż niemiecka”; , Kultura to zbiór norm i zasad zachowania. [...] Kultura kojarzy mi się przede wszystkim z literaturą, kościołami, malarstwem, muzyką klasyczną itd.". Zebrane wyniki potwierdzają jedynie częściowo postawioną przed przeprowadzeniem badania tezę, tzn. z jednej strony studenckie skojarzenia związane ze słowem kultura zawierają oprócz potocznych stwierdzeń także te opierające się na rozważaniach i definicjach naukowych. $Z$ drugiej zaś strony podawane przez badanych skojarzenia i definicje nie zawsze są przez nich poprawnie rozumiane. Oznacza to, że u podstaw wielu studenckich interpretacji leży wiedza szablonowa, nie zaś pogłębiona, czego w zasadzie należałoby oczekiwać od studentów filologii.

\section{Wnioski}

Zebranych w badaniu wyników nie można wprawdzie uznać za reprezentatywne z powodu doboru próby, jednak ukazują one pewne tendencje panujące wśród przyszłych filologów, w większości (70\%) przyszłych nauczycieli języka niemieckiego. W związku z tym niepokoi fakt, że kulturę sprowadzają oni do wewnętrznie jednolitej kultury narodowej oraz że wydają się postrzegać produkty materialne, a nie mentalne, jako zasadniczy element kultury, mimo sformułowanego przez większość badanych stwierdzenia, że kultura to zbiór norm i zasad zachowania. Można zatem przypuszczać, że jako przyszli nauczyciele języka niemieckiego będą zapoznawać swoich uczniów z homogeniczną kulturą niemiecką (w najlepszym wypadku austriacką i szwajcarską), którą sprowadzą do wytworów materialnych (głównie atrakcji turystycznych) oraz ciekawostek o podłożu stereotypowym, a pominą kwestie podobieństw i różnic w zachowaniu i postrzeganiu rzeczywistości przez Niemców, Polaków i przedstawicieli innych narodowości.

Taka perspektywa, ograniczająca się do kultury narodowej oraz wytworów materialnych kultury danego kraju, jest niestety preferowana w niektórych programach i podręcznikach do nauki języka niemieckiego jako obcego (Mihułka, 2012a: 117-156). Konieczne jest zatem uwzględnienie w procesie nauczania i uczenia się języka obcego (niemieckiego), poczynając od dokumentów regulujących kształcenie językowe w Polsce, programów nauczania, podręczników, a na centralnych elementach układu glottodydaktycznego (tj. na nauczycielu i uczniu) kończąc, następujących kwestii: 
Kultura to nie wielkość jednorodna, lecz wielkość wewnętrznie wysoce zróżnicowana. $\mathrm{Na}$ lekcjach języka obcego wybierana jest perspektywa polityczna podczas określania obszaru kultury, czego następstwem jest ujmowanie jej jako kultury narodowej. Kultura własna (polska) przeciwstawiana jest więc kulturze obcej (np. niemieckiej). Takie zabiegi wydają się z jednej strony logiczne, gdyż pozwalają sprowadzić złożoność kultury danego kraju tylko do właściwości podzielanych przez większość jego mieszkańców (zapewniają więc ogólną orientację). Z drugiej zaś strony ograniczanie się tylko do tego, co typowe dla danej kultury, sprzyja generalizacji i stereotypizacji, a oferowany obraz danej nacji jest dość mocno zniekształcony. W obrębie każdej kultury można bowiem wyróżnić szereg subkultur, charakteryzujących się swoimi własnymi sposobami działania i postępowania, tzn. takimi, które w mniej lub bardziej wyraźny sposób różnią się od norm przyjętych przez większość członków danej grupy narodowej. Ponadto należy pamiętać o tym, że kultura jest wyrazem nie tylko kolektywnych, lecz także indywidualnych potrzeb, które podlegają dużemu jednostkowemu zróżnicowaniu. Dlatego zadaniem każdego nauczyciela języka obcego jest przeciwdziałanie sztywnej kategoryzacji kultur poprzez nieustanne podkreślanie różnorodności tej jedynie na pierwszy rzut oka homogenicznej struktury danej kultury narodowej. Lekcja języka obcego daje dodatkowe możliwości uwrażliwiania uczniów na Inność oraz uświadamiania im, że odmienny od naszego sposób myślenia i wartościowania wcale nie musi być gorszy, pozbawiony sensu, dziwny czy wręcz głupi ${ }^{9}$.

\section{Kultura to wynik wszelkich przekształceń natury przez człowieka.}

Należy jednoznacznie podkreślić, że pod pojęciem natury rozumiemy zarówno naturę otaczającą człowieka, jak i naturę wewnętrzną człowieka. Niestety, na lekcji języka obcego przywoływane jest najczęściej tylko jej pierwsze rozumienie. Stosunkowo dużo mówi się o materialnych wytworach kulturowych (najczęściej tych spektakularnych), dających się nierzadko sprowadzić do ikon turystycznych i symboli kraju, regionu, miasta, a pomija się mentalne wytwory. Chodzi o zbiory zasad, reguł, wartości wypracowanych i stworzonych przez członków danej wspólnoty, które regulują sposób ich myślenia, postrzegania rzeczywistości i zachowania językowego i niejęzykowego, a więc determinują jakość relacji międzyludzkich.

\section{Kultura to zjawisko dynamiczne.}

Na lekcji języka obcego należy uwypuklać fakt, że każda kultura nieustannie ewoluuje pod wpływem czynników wewnętrznych i zewnętrznych. Zmienia się

${ }^{9}$ Ciekawe propozycje zadań sprzyjających rozwijaniu kompetencji interkulturowej można znaleźć np. w: Hiller i Vogler-Lipp, 2010; Mihułka, 2012b. 
zatem sposób myślenia, wartościowania, postrzegania członków danej wspólnoty kulturowej, co manifestuje się w ich wytworach materialnych oraz zachowaniach. Na lekcji języka niemieckiego wystarczy np. przytoczyć uczniom definicje kultury z okresu narodowego socjalizmu, aby pokazać, jak duży, a zarazem negatywny wpływ nie tylko na postrzeganie świata, ale i na konkretne działania ludzkie, miała ideologia faszystowska.

Przedstawione powyżej propozycje zmian pozwolą, moim zdaniem, na pełniejsze uchwycenie wieloznacznego słowa kultura oraz na poprawne osadzenie go w kontekście nauczania i uczenia się języka obcego. Daleka jestem od tego, aby dążyć do wybrania „jednej właściwej” definicji kultury, gdyż takiej nie ma, jednak uważam, że na potrzeby dydaktyki języków obcych konieczne jest nazwanie i zdefiniowanie tych elementów kultury, które są kluczowe w procesie nauczania i uczenia się języka obcego. Pozwoliłoby to uniknąć niekiedy dość niefortunnych ujęć kultury prezentowanych w programach i podręcznikach do nauki języków obcych (Aleksandrowicz-Pędich, 2005, 2007; Mihułka, 2012a: 155156), które nie pomagają nauczycielom języków obcych we właściwej interpretacji pojęcia kultura, lecz wprowadzają jeszcze większy chaos.

\section{BIBLIOGRAFIA}

Aleksandrowicz-Pędich, L. 2005. Międzykulturowość na lekcjach języków obcych. Białystok: Wydawnictwo Uniwersytetu w Białymstoku.

Aleksandrowicz-Pędich, L. 2007: „Interkulturowość w kształceniu językowym w Polsce i innych krajach europejskich". (w) Nauczanie języków obcych - Polska a Europa. (red. H. Komorowska). Warszawa: Wydawnictwo SWPS Academica, str. 39-56.

Altmayer, C. 1997. „Zum Kulturbegriff des Faches Deutsch als Fremdsprache“. Zeitschrift für Interkulturellen Fremdsprachenunterricht, 2: 1-25. [online: http://zif.spz.tu-darmstadt.de/jg-02-2/beitrag/almayer3.htm; DW 24.09.2011].

Altmayer, C. 2004. Kultur als Hypertext. Zu Theorie und Praxis der Kulturwissenschaft im Fach Deutsch als Fremdsprache. München: iudicium.

Auernheimer, G. 1988. Der sogenannte Kulturkonflikt. Orientierungsprobleme ausländischer Jugendlicher. Frankfurt - New York: Campus.

Baecker, D. 2003. Wozu Kultur? Berlin: Kadmos.

Bausinger, H. 1975. „Zur Problematik des Kulturbegriffs”. Jahrbuch Deutsch als Fremdsprache, 1: 7-16.

Bolten, J. 2006. Interkulturowa kompetencja. Poznań: Wydawnictwo Naukowe UAM.

Bolten, J. 2014: „»Kultur « kommt von colere: Ein Plädoyer für einen holistischen, nicht-linearen Kulturbegriff". (w) Kultur und Interkulturalität. Interdisziplinäre Zugänge. (red. E. Jammal). Wiesbaden: Springer Fachmedien, str. 85-107.

Bonacchi, S. 2011. Höflichkeitsausdrücke und anthropozentrische Linguistik. Warszawa: Euro_edukacja. 
Broszinsky-Schwabe, E. 2011. Interkulturelle Kommunikation. Missverständnisse - Verständigung. Wiesbaden: VS Verlag für Sozialwissenschaften, Springer Fachmedien.

Dakowska, M. 2008. Psycholingwistyczne podstawy dydaktyki języków obcych. Warszawa: PWN.

Grucza, F. 1989: „Język a kultura, bilingwizm a bikulturyzm: lingwistyczne i glottodydaktyczne aspekty interlingwalnych i interkulturowych różnic oraz zbieżności". (w) Bilingwizm, bikulturyzm, implikacje glottodydaktyczne. Materiały z XII Sympozjum zorganizowanego przez Instytut Lingwistyki Stosowanej UW Zaborów, 18-20 września 1986 r. (red. F. Grucza). Warszawa: Wydawnictwa Uniwersytetu Warszawskiego, str. 9-49.

Grucza, F. 1992: „Kulturowe determinanty języka oraz komunikacji językowej”. (w) Język, kultura - kompetencja kulturowa. Materiały z XIII Sympozjum zorganizowanego przez Instytut Lingwistyki Stosowanej UW Zaborów, 5-8 listopada 1987 r. (red. F. Grucza). Warszawa: Wydawnictwa Uniwersytetu Warszawskiego, str. 9-70.

Haller, P.-M. i U. Nägele. 2013. Praxishandbuch Interkulturelles Management. Der andere Weg: affektives Vermitteln interkultureller Kompetenz. Wiesbaden: Springer Fachmedien.

Hiller, G.-G. i S. Vogler-Lipp. 2010. Schlüsselqualifikation Interkulturelle Kompetenz an Hochschulen. Grundlagen, Konzepte, Methoden. Wiesbaden: Verlag für Wissenschaften.

Hofstede, G. 1993. Interkulturelle Zusammenarbeit: Kulturen-Organisationen-Management. Wiesbaden: Gabler.

Komorowska, H. 1982. Metody badań empirycznych w glottodydaktyce. Warszawa: PWN. Krezenbacher, H.-L. 1992. „Der »erweiterte Kulturbegriff« in der außenkulturpolitischen Diskussion der Bundesrepublik Deutschland. Ein Vergleich mit der öffentlichen / innenkulturpolitischen und kulturwissenschaftlichen Begriffsentwicklung von den sechziger bis zu den achtziger Jahren“. Jahrbuch Deutsch als Fremdsprache, 18: 170-196.

Kroeber A.-L. i C. Kluckhohn. 1952. Culture a Critical Review of Concepts and Definitions. Cambridge, Massachusetts: Peabody Museum of Archaeology and Ethnology.

Kübler, H.-D. 2011. Interkulturelle Medienkommunikation. Eine Einführung. Wiesbaden: Verlag für Sozialwissenschaften.

Lexis, W. 1906: „Das Wesen der Kultur“. (w) Die allgemeinen Grundlagen der Kultur der Gegenwart. (red. W. Lexis i inni). Berlin - Leipzig: B. G. Teubner, str. 1-53.

Łobocki, M. 2009. Wprowadzenie do metodologii badań pedagogicznych. Kraków: Oficyna Wydawnicza Impuls.

Meyers Lexikon. 1924. Leipzig: Bibliographisches Institut AG.

Meyers Lexikon. 1939. Leipzig: Bibliographisches Institut AG.

Mihułka, K. 2012a. Rozwój kompetencji interkulturowej w warunkach szkolnych. Mity a polska rzeczywistość. Rzeszów: Wydawnictwo Uniwersytetu Rzeszowskiego.

Mihułka, K. 2012b. „Sposoby rozwijania kompetencji interkulturowej na lekcji języka obcego." Języki Obce w Szkole, 2: 106-117.

Nieke, W. 2008. Interkulturelle Erziehung und Bildung. Wertorientierungen im Alltag. Wiesbaden: VS Verlag für Sozialwissenschaften, GWV Fachverlage GmbH.

Nikitorowicz, J. 2007. Edukacja międzykulturowa. Kreowanie tożsamości dziecka. Gdańsk: GWP. 
Nikitorowicz, J. 2009. Edukacja regionalna i międzykulturowa. Warszawa: Wydawnictwa Akademickie i Profesjonalne.

Nowicka, E. 2006. Świat człowieka - świat kultury. Warszawa: PWN.

Roche, J. 2006: „Interkulturelle Kompetenz“. (w) Praktische Handreichung für Fremdsprachenlehrer. (red. U. O. H. Jung). Frankfurt am Main: Peter Lang Verlag, str. 422-429.

Roth, H.-J. 2002. Kultur und Kommunikation. Systematische und theoriegeschichtliche Umrisse interkultureller Pädagogik. Wiesbaden: Springer Fachmedien (Interkulturelle Studien, Band 10).

Tarasiewicz, P. 2011. „»Kultura« i »cywilizacja« - próba korelacji“. Roczniki Kulturoznawcze, II: 71-88.

Thomas, A. 1994. „Ist Toleranz ein Kulturstandard?“. Jahrbuch Deutsch als Fremdsprache, 20: 153-175.

Thomas, A. 2003: „Analyse der Handlungswirksamkeit von Kulturstandards“. (w) Psychologie interkulturellen Handelns. (red. A. Thomas). Göttingen: Hogrefe Verlag für Psychologie, str. 107-135.

Tylor, E.-B. 1871. Primitive Culture. London: J. Murray.

Weber, H. 1976: „Interkulturelle Kommunikation und Landeskunde“. (w) Landeskunde im Fremdsprachenunterricht. Kultur und Kommunikation als didaktisches Konzept. (red. H. Weber). München: Kösel Verlag, str. 214-224.

Wilczyńska, W. i A. Michońska-Stadnik. 2010. Metodologia badań w glottodydaktyce. Wprowadzenie. Kraków: AVALON.

Wolf, G. 2010: „Vergleichende Kultur- und Mentalitätsforschung“. (w) Deutsch als Fremd- und Zweitsprache. Ein internationales Handbuch. Band 2. (red. H.-J. Krumm, Ch. Fandrych, B. Hufeisen i C. Riemer). Berlin - New York: Walter de Gruyter, str. 1431-1440. 